\title{
ECONOMIC AND ENVIRONMENTAL EFFECTS OF RURAL-URBAN MIGRANT TRAINING
}

\author{
Xiaochun Li, Yu Zhou*
}

\begin{abstract}
:
In this paper, we conduct the simple comparative static analysis of the environmental and economic effects of the government and producer services sector's training of rural-urban migrants. We mainly focus our attention on environmental issues and reach the following conclusions: When the government lowers the interest rate of training loans, environmental conditions will worsen. However, when the producer services sector increases the unit cost of training rural labour, the opposite effect occurs, and environmental conditions will improve. In addition, we discuss the conditions under which a government reduction in the interest rate of training loans will lead to the reduction of pollution damage to agricultural production and a decrease in social utility.
\end{abstract}

Keywords: environment effects, low interest rate loan, employee vocational training, rural-urban migration.

JEL Classification: J24, R23

\section{Introduction}

Harris and Todaro (1970) presented a simple dual-economy model of rural-urban migration with a long-run equilibrium characterized by the existence of urban unemployment. This model corresponds with the existence of persistent urban unemployment in many developing countries. Consequently, the model has attracted the attention of many economists with an interest in the problems of developing countries. Two important issues relating to the Harris-Todaro model are the regulation of environment pollution caused by the production of intermediate goods and the relationship between human capital investment and rural-urban migration. ${ }^{1}$

* Department of Economics, Nanjing University, 22 Hankou Road, Nanjing, Jiangsu Province 210093, China.

The authors thank two anonymous PEP referees for their constructive suggestions and PEP Managing Editor Milan Kolar for the generous help. The authors also express the thanks to the financial supports provided by the Key Project of 2009 for Key Research Bases for Humanities and Social Sciences of the Ministry of Education No. 2009JJD7900 and the National Social Sciences Fund Project No. 10BJL035.

1 In the present paper, human capital investment refers purely to the vocational training. Generally speaking, the human capital level is roughly measured by the educational year, and here we treat the vocational training as a way to compensate for the lack of educational year. 
of intermediate goods, Dean and Gangopadhyay (1997) used a three-sector model to analyse how limiting the export of intermediate goods would affect environmental pollution, rural-urban migration and urban unemployment. Chao (2003) also established a three-sector model analysing the economic effects of imposing a production tax on intermediate goods. Later, Chaudhuri and Mukhopadhyay (2006) analysed the efficiency of imposing a pollution emission tax on the formal manufacturing sector in a three-sector general equilibrium model that included pollution effects from the informal sector. Earlier empirical researches, such as Papola (1981) and Romatet (1983), suggested that the urban informal sector produced intermediate goods for the formal manufacturing sector and that, in fact, the informal sector was the main source of environmental pollution.

In studies of the relationship between human capital investment and rural-urban migration, Bhagwati and Srinivasan (1977) studied how education affected the job search process of individuals, from which they developed the now-famous job ladder model. Djajic (1985) investigated the relationship between vocational training of employees in the production sector and urban unemployment under the assumption of a minimum wage act. Samanta (2003) analysed the economic effects of the training of urban sector employees, under the assumption of perfect competition in the agricultural sector and imperfect competition in the urban sector.

However, the above mentioned research is not as relevant in analysing issues prevalent in developing economies. Currently, developing countries emphasize the development of the producer services sector, and the development of the producer services sector must face problems with differences in human capital originating from rural and urban areas and with environmental pollution.

With the development of the knowledge economy, the producer services sectors in the developing countries have become increasingly technologically intensive, and correspondingly demand a higher level of human capital. The development of the producer services sector depends on absorbing the rural-urban migrants, yet the lack of education of many rural migrants is an impediment to sector growth, especially within China. In 2007, the average migrant had approximately 7.7 years of education (up from 6.46 years in 1997) compared to the 13.44 years of education the average urban worker enjoyed (itself an increase from 11.42 ten years prior). The average rural migrant had the equivalent of a junior middle school level education, whereas the average urban resident had an education above the high school level (Xiaochun Li and Xiaoying Qian, 2011). This gap in education is thought to be a key reason behind the lagging growth ratio of producer services output value compared to GDP for the past twenty years (Zhibiao Liu, 2011).

Compounding the education gap is the environmental issue. In the short run, the expansion of the manufacturing sector will generate more pollution, which is known as the scale effect of environmental pollutions (Grossman and Kruger, 1993). Given the vertical linkage between the producer services sector and the manufacturing 
sector, an expanding services sector will lead to an increase in its output, which is expected to further lead to an increase in manufacturing activity, the consequence of which is the deterioration of the environment. With the development of the producer services sector, the manufacturing sector would generate more pollution. Here we call such kind of the environmental pollution "the producer services sector-induced environmental pollution". Thus, in finding solutions to the development bottleneck of the producer servicers sector, we need to balance out a need to improve the quality of migrant human capital with the need to reduce producer-service-sector-induced environmental pollution. Given the possibility of a vicious cycle, it is impossible to ignore the confluence of these two factors.

Despite the relative wealth of research about the two aforementioned issues individually, there is still no research attempting to combine the factors of rural-urban migration, employee vocational training (or the human capital investment), and corresponding environmental effects into a unifying framework.

In order to fill the current research gap, the present paper presents a model integrating the rural urban migration, vocational training of rural-urban migrants employed by the producer services sector and environmental pollution into the general equilibrium framework of an extended Harris-Todaro model under the profit maximization condition. There are two situations under consideration.

In the first situation, the producer services sector will borrow all money from banks for training rural-urban migrants to meet the minimum human capital required by the production of the producer services sector. The producer services sector will stop training the rural-urban migrants when these migrants meet that human capital level. Given the unit cost of training a rural employee, the government will intervene in the bank system and lower the interest rate of loans for training services (here after in the "low interest rate policy").

In the second situation, the producer services sector will train the rural-urban migrants with their own capital to meet the necessary level of human capital according to the firm's business scale and financial status, given the interest rate of the loan. In this situation, the firms are expected to create a training plan to fulfil their goals, and this plan will decide the unit training cost of transferred labour (here after in "firm's human capital investment").

The present paper is to try to find out the economic and environmental impacts exerted by the government and firms' efforts to raise the human capital level. The reason that we take the government's low interest rate policy is that this policy is not only aimed at increasing the amount of employment of the producer services sector, but also this is more applicable in certain Asian countries, such as Japan and Korea that feature the implementation of policy that supports the development of medium-sized and smallsized enterprises. Recently, the Chinese government also has begun using similar policies to encourage medium-scale and small-scale enterprises to develop new energy 
projects ${ }^{2}$. Thus, we propose that government policies offering low interest rate loans to the producer services sector to train rural employees will probably be implemented by developing countries in the future.

Our main result is that environmental effects generated by the producer services sector's employee vocational training of rural-urban migrants depend on the training approach. When the government lowers the interest rate of training loans, environmental conditions will worsen. However, when the producer services sector performs human capital investment, the environment condition will improve.

Besides the theoretical extension of the current researches, in the present paper, we also draw a picture to illustrate the labour allocation mechanism of the three sectors, which can be regarded as an extension of that in Xiaochun Li and Xiaoying Qian (2011) by taking the environment pollution into consideration.

The rest of this paper is organized as follows: in Section 2, we set up a theoretical model in an extended Harris-Todaro framework; in Section 3, we conduct a simple comparative static analysis of decreasing the government training loan interest rate and increasing the unit cost of training a rural worker by the producer services sector; and in section 4 , we provide concluding remarks.

\section{Theoretical Model}

We will consider a small, and open economy consisting of three sectors: the rural agricultural sector, the urban producer services sector, and the urban manufacturing sector. The agricultural sector utilizes rural labour and sector-specific capital as factors of production, and its wage rate is flexible. The producer services sector produces intermediate goods used as input in the manufacturing sector and utilizes urban labour, trained rural-urban migrants, and sector-specific capital as factors of production. The manufacturing sector utilizes urban labour, rural-urban migration, sector-specific capital, and intermediate goods as factors of production. The wage rate of the manufacturing sector is downward rigid $^{3}$. We furthermore assume that only the production procedure of the agricultural sector depends on environmental factors. That is to say, improvements within the rural environment will create correspondingly higher levels of output. Production from the producer services sector does not generate pollution. However, manufacturing production will generate pollution, which imposes damage to the rural environment through factors such as air and water.

2 Detailed information can be referred to http://zhcfg.esepworld.com/zhcgch/182795/index.html.

3 In the present paper, we assume that the wage rate of the manufacturing sector is downward rigid because people who are employed in the urban sectors usually receive contractually-obligated wage rates or are protected by minimum wage acts or the labour union in urban areas. The same assumption of the downward rigid manufacturing wage rate (especially in the frame of Harris-Todaro model) can be also found in Grinols (1991), Gupta (1993), Tawada and Sunqin (2010), Xiaochun Li and Xiaoying Qian (2011) etc. 
We assume that initially the amount of employment in the urban producer services sector, the urban manufacturing sector, and the rural agricultural sector, are $\bar{L}_{1}, \bar{L}_{2}$ and $\bar{L}_{3}$, respectively. The corresponding level of urban unemployment is $\bar{L}_{U}$. The price of agricultural good is normalized to be unit. In the following part, we will only focus our attention to the issues of rural-urban migrants.

\subsection{Producer Services Sector}

Because of the urban and rural disparity in education, the human capital level of urban workers is higher than that of the rural workers (Xiaochun Li and Xiaoying Qian, 2011). We assume that the urban workers could be employed in the producer services sector directly, while the rural labour could enter into the producer services sector only by means of vocational training. The production function of this sector is:

$$
Y_{1}=F^{1}\left(h L_{1}, \bar{K}_{1}\right)
$$

Where $Y_{1}, L_{1}$ and $\bar{K}_{1}$ are the levels of output, labour, and capital employed, respectively. $h$ expresses the efficiency of each worker after vocational training, that is, the minimum per capita human capital level needed by the producer services sector. Here, $h L_{1}$ is the human capital stock in that sector. $h$ depends upon the unit cost of training a rural worker:

$$
h=h(c)
$$

Here, $c$ is the unit cost of training a rural labour. $h(\cdot)$ satisfies the conditions $h(0)=1$, $h^{\prime}>0$ and $h^{\prime \prime}<0$. The wage rate of employees in the producer services sector is $h \bar{w}$. The establishment of the wage rate of employees who have a high level of human capital in equation (2) is in accord with the parameters established in Galor and Moav (2004). If the government gives producer services a loan with interest $i$, we have

$$
p_{1} h F_{L}^{1}-(1+i) c=h \bar{w}
$$

Where $p_{1}$ is the relative price of the producer services product in terms of agricultural products. From here on, $F_{L}^{i}=\frac{\partial F^{i}}{\partial L_{i}}, i=1,2,3$.

\subsection{Manufacturing Sector}

The production function of this sector is given by the equation:

$$
Y_{2}=F^{2}\left(L_{2}, T, \bar{K}_{2}\right)
$$


Where $Y_{2}, L_{2}$ and $\bar{K}_{2}$ are the levels of output, labour, and capital employed, respectively, and $T$ is the amount of intermediate input. For the sake of simplicity, we assume that $F_{L T}^{2}=0$ (Gupta, 1993), where $F_{I T}^{2}=\frac{\partial^{2} F^{2}}{\partial L \partial T}$. Profit maximization yields:

$$
\begin{aligned}
& p_{2} F_{L}^{2}=\bar{w} \\
& p_{2} F_{T}^{2}=p_{1}
\end{aligned}
$$

Where $p_{2}$ is the relative price of manufacturing products in terms of agricultural products and $F_{T}^{2}=\frac{\partial F^{2}}{\partial T}$. Furthermore, we can obtain the following input demand function by rewriting equation (6) as follows:

$$
T=T\left(p_{1}\right)
$$

Where $T^{\prime}<0$. In equilibrium, the output of the producer services sector is equal to the demand for its product by the manufacturing sector. Hence,

$$
Y_{1} \quad T\left(p_{1}\right)
$$

\subsection{Agricultural Sector}

The production function of this sector is given by:

$$
Y_{3}=g(E) F^{3}\left(L_{3}, \bar{K}_{3}\right)
$$

Where $Y_{3}, L_{3}$ and $\bar{K}_{3}$ are the levels of output, labour, and capital employed, respectively. $\mathrm{E}$ is denoted as the quality of the rural environment after pollution. $g(E)$, with the properties of $g>0, g^{\prime}>0$ and $g^{\prime \prime}<0$, represents the effect of the rural environment on agricultural productivity. Thus:

$$
E=\bar{E}-\lambda Y_{2}
$$

Where $\bar{E}$ is the best quality of the rural environment, which is regarded as given. $\lambda$ expresses the units of local pollution generated by one unit of production of the manufacturing sector. Taking the effect of rural environment on agricultural productivity into consideration, the denotation of equation (10) here is in accord with Copeland and Taylor (1999) and Tawada and Shuqin Sun (2010). Profit maximization yields:

$$
g F_{L}^{3}=w_{a}
$$

Where $w_{a}$ is the wage rate. 


\subsection{Labour Market}

The full-employment condition can be written as:

$$
L_{1}+L_{2}+L_{3}+L_{U}=\bar{L}
$$

Where $L_{U}$ is the amount of urban unemployment.

The Harris-Todaro labour allocation mechanism in three sectors yields:

$$
w_{a}=\frac{L_{1}-\bar{L}_{1}}{\bar{L}_{3}-L_{3}} h \bar{w}+\frac{L_{2}-\bar{L}_{2}}{\bar{L}_{3}-L_{3}} \bar{w}
$$

Here, $L_{1}-\bar{L}_{1}, L_{2}-\bar{L}_{2}$ and $\bar{L}_{3}-L_{3}$ represent the amount of rural-urban migrants employed by the producer services sector, the manufacturing sector, and the total amount of rural transferred labour, respectively. $\frac{L_{1}-\bar{L}_{1}}{\bar{L}_{3}-L_{3}}$ and $\frac{L_{2}-\bar{L}_{2}}{\bar{L}_{3}-L_{3}}$ can be regarded as the probability of rural-urban migrants to be employed by the producer services sector and of the rural-urban migrants to be employed by the manufacturing sector. This equilibrium migration equation is also used by Xiaochun Li and Xiaoying Qian (2011).

The basic model has been established. Twelve equations (1), (2), (3), (4), (5), (7), (8), (9), (10), (11), (12) and (13) determine twelve endogenous variables, $L_{1}, L_{2}, L_{3}, L_{U}$, $w_{a}, p_{1}, h, E, T, Y_{1}, Y_{2}$ and $Y_{3}$. The exogenous variables are $i$ and $c$.

Now we will use the following figures to illustrate the rural-urban migration equilibrium, and the corresponding environmental impact.

In Figure 1, we first draw the mechanism of labour allocation in the initial phase. According to our pre-assumptions, in the initial phase, the labour employment in the producer services sector, the manufacturing sector and the agricultural sector are denoted as $\bar{L}_{1}, \bar{L}_{2}$ and $\bar{L}_{3}$ respectively. The amount of the initial urban unemployment is $\bar{L}_{U}$. Here we assume that in the initial phase, labour has not been transferred from rural areas to urban areas yet, and the government does not offer the loan of low interest rate to the enterprises in the producer services sector. At this time, the environment has not been deteriorated. Equations (3), (5) and (11) will be rewritten as $p_{1} F_{L}^{1}\left(\bar{L}_{1}, \bar{K}_{11}\right)=\bar{w}$, $p_{2} F_{L}^{2}\left(\bar{L}_{2}, \bar{T}_{11}, \bar{K}_{12}\right)=\bar{w}$, and $g(\bar{E}) F_{L}^{3}\left(\bar{L}_{3}, \bar{K}_{13}\right)=w_{0 a}$, respectively. These three equations represent the values of the marginal product of labour in the producer services sector, the manufacturing sector, and the agricultural sector, respectively. Here $\bar{K}_{1 i}(i=1,2,3)$ represent the sector-specific capital employed by the producer services sector, the manufacturing sector, and the agricultural sector, respectively. $\bar{T}_{11}$ is the amount of the intermediate input used by the manufacturing sector. $w_{0 a}$ is the wage rate of the agricultural sector, satisfying $w_{0 a}<\bar{w} . \bar{E}$ is the best quality of the environment. Because the production functions satisfy the properties of strict concavity and linear homogeneity, the lines representing the values of the marginal product of labour in the above three sectors have negative slopes. In Figure 1, the 
horizontal axis is the labour endowment, that is, $O_{1} O_{2}=\bar{L}$. We can find three points in the horizontal axis, $A, B$, and $C$, which satisfy $O_{1} A=\bar{L}_{1}, A B=\bar{L}_{2}, O_{2} C=\bar{L}_{3}$ and $B C=\bar{L}_{U}$. The vertical axis crossing point $O_{1}$ represents the wage rate of the producer services sector. We can find a point $D$ that satisfies $O_{1} D=\bar{w}$ in the vertical axis crossing $O_{1}$. Then, drawing a line through $D$ and parallel to $O_{1} O_{2}$ interacts at point $E$ with the axis that is through $A$ and perpendicular to $O_{1} O_{2}$. According to $p_{1} F_{L}^{1}=\bar{w}$, we can draw a downward sloping line $t t$ passing through $E$, which stands for the value of the marginal labour in the producer services sector. We use the vertical axis through $E$ to represent the manufacturing wage rate. Drawing a line through $E$ and parallel to $O_{1} O_{2}$ interacts at point $F$ with the line that is through $B$ and perpendicular to $O_{1} O_{2}$. From $p_{2} F_{L}^{2}=\bar{w}$, we can draw a downward sloping line $\mathrm{mm}$ passing through $F$ to depict the value of the marginal labour in the manufacturing sector. We use the vertical axis through $\mathrm{O}_{2}$ to represent the agricultural wage rate. Then we can find a point $H$ in the vertical axis crossing $\mathrm{O}_{2}$, satisfying $\mathrm{O}_{2} H=\bar{w}_{a}$. Drawing a line through $\mathrm{H}$ and parallel to $O_{1} O_{2}$ interacts at point $G$ with the line through $C$ and perpendicular to $O_{1} O_{2}$. From $g F_{L}^{3}=\bar{w}_{a}$, we can draw a downward sloping line a a passing through $G$, which stands for the value of the marginal labour in the agricultural sector.

Figure 1

Initial Labour Allocation Mechanisms

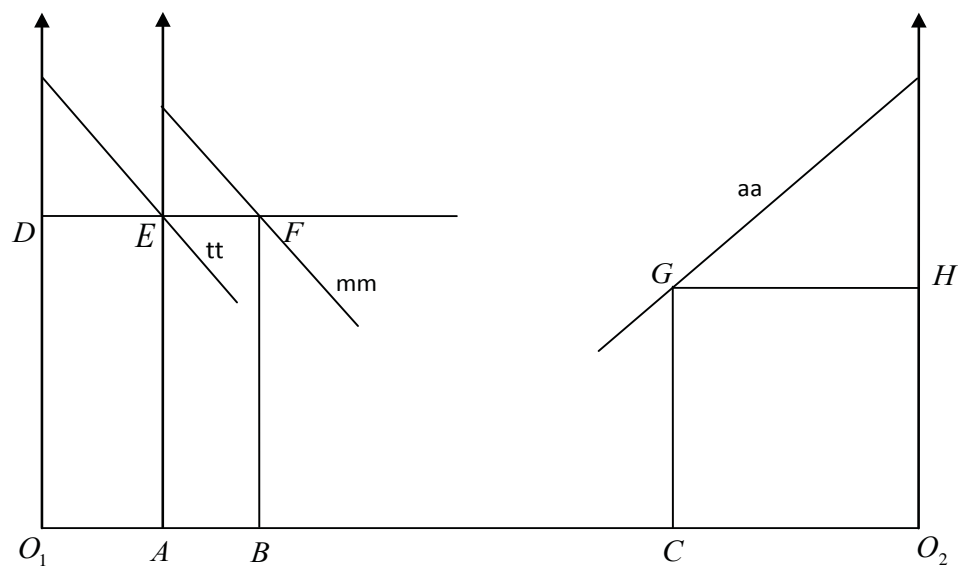

With the help of Figure 1, now we consider the economic and environmental impacts exerted by the rural-urban migration, the low-interest-rate loan to the producer services sector offered by the government, and the vocational training of rural employees employed by the producer services firms. Figure 2 illustrates the labour allocation mechanism of three sectors shown by equation (13) and the loss of agricultural production due to the environmental pollution. Figure 2 can be regarded as an extension of that in Xiaochun Li and Xiaoying Qian (2011) by considering the impact of environmental pollution. 
By substituting equation (12) into equation (13), we can derive the following equation:

$$
\left(h \bar{w}-w_{a}\right)\left(L_{1}-\bar{L}_{1}\right)+\left(\bar{w}-w_{a}\right)\left(L_{2}-\bar{L}_{2}\right)=w_{a}\left(L_{U}-\bar{L}_{U}\right)
$$

Consistent with Figure 1 , we have $O_{1} A=\bar{L}_{1}, A B=\bar{L}_{2}, O_{2} C=\bar{L}_{3}$ and $B C=\bar{L}_{U}$ in Figure 2. The dotted lines, $t$ t, $\mathrm{mm}$ and $a a$, represent the values of the marginal product of labour in the producer services sector, the manufacturing sector and the agricultural sector, respectively. From Appendix A, we can get the equilibrium values of $p_{1}, L_{1}, L_{U} w_{a}$, and $L_{3}$.

At this time, because of the low-interest-rate loan to the producer services sector offered by the government, and the vocational training to the rural employees employed by the producer services firms, the value of the marginal labour in the producer services sector increases, leading line $t t$ to shift rightwards to line $t t^{\prime}$. The derivation of line $t t^{\prime}$ is as follows. Find a point $A^{\prime}$ on the right side of $O_{1}$, such that $O_{1} A^{\prime}=L_{1}$. Thus, $A A^{\prime}=L_{1}-\bar{L}_{1}$. Given $\bar{w}$ and $c$, we can calculate $h$ from equation $h=h(c)$. We use $A$ as the original point to make a vertical line and find a point $G$ on this line, such that $A G=h \bar{w}$. According to equation (3), we can derive the value of the marginal product of labour in the producer services sector as line $t t^{\prime}$.

Furthermore, due to economic development and the increase in the labour employment of the producer services sector attributing to the shift of the vertical axis that represents the wage rate of the manufacturing sector, line $\mathrm{mm}$ moves rightwards to line $\mathrm{mm}^{\prime}$. Use $A^{\prime}$ as the original point to make a vertical axis, which interacts with a line passing $G$ and parallel to $O_{1} O_{2}$ at $H$. Find a point $A^{\prime \prime}$ on the right side of $A^{\prime}$, such that $A^{\prime} A^{\prime \prime}=A B\left(=\bar{L}_{2}\right)$. Use $A^{\prime} H$ as the vertical axis, representing the manufacturing wage. From equation (5), we can draw a downward-sloping line $\mathrm{mm}$ ' to represent the value of the marginal product of labour in the manufacturing sector. Drawing a line through $D$ and parallel to $O_{1} O_{2}$ meets the line passing through and perpendicular to $A^{\prime \prime}$ at $L$, which also crosses line $m m^{\prime}$ at $M$. Drawing a line through $M$ and perpendicular to $O_{1} O_{2}$, it meets $O_{1} O_{2}$ at $B^{\prime}$, and thus $A^{\prime} B^{\prime}=L_{2}$. It is evident that $A^{\prime \prime} B^{\prime}=L_{2}-\bar{L}_{2}$. Use $O_{2}$ as the original point and derive $C^{\prime}$ on the left side of $O_{1} O_{2}$, such that $O_{2} C^{\prime}=L_{3}$. Thus, we have $B^{\prime} C^{\prime}=L_{U}$. We can find a point $I$ on the right side of $B^{\prime}$, such that $B^{\prime} I=B C$. Thus, $C^{\prime} I=L_{U}-\bar{L}_{U}$. From equation (11), we can derive the value of the marginal product of labour aa'. Because agricultural production suffers from the deterioration of the rural environment in this phase, the value of the marginal labour in the agricultural sector decreases. Therefore, compared with line $a a$, line $a a^{\prime}$ ' will shift rightward. We draw a line passing $C^{\prime}$ and perpendicular to $O_{1} O_{2}$, which meets aa' at $R^{\prime}$. Hence, $C^{\prime} R^{\prime}=w_{a}$. Furthermore, drawing a line through $R^{\prime}$ and perpendicular to $O_{1} O_{2}$ meets $a a, M B^{\prime}, L A^{\prime \prime}, H A^{\prime}, G A$ and the right vertical axis ( $O_{2}$ the point of origin) at $Q, N, P, J$ and $S^{\prime}$. Thus, $\left(h \bar{w}-w_{a}\right)\left(L_{1}-\bar{L}_{1}\right)$, $\left(\bar{w}-w_{a}\right)\left(L_{2}-\bar{L}_{2}\right)$ and $w_{a}\left(L_{U}-\bar{L}_{U}\right)$ are represented by the shaded areas, $S_{G H K J}, S_{L M N P}$ and $S_{Q R^{\prime} C^{\prime} D}$, respectively. According to equation (13'), we have $S_{G H K J}+S_{L M N P}=S_{Q R^{\prime} C^{\prime} D}$. Draw a line through $C^{\prime}$ and perpendicular to $O_{1} O_{2}$. It meets $a a$ at $U$. Draw a line through $U$ and perpendicular to $O_{1} O_{2}$. It meets $O_{2} S^{\prime}$ at $T$. The shaded area $S_{U T S^{\prime} R^{\prime}}$ represents the loss of agricultural production due to the environmental pollution. 


\section{Figure 2}

Labour Allocation Mechanisms of Three Sectors and the Loss of Agricultural Production

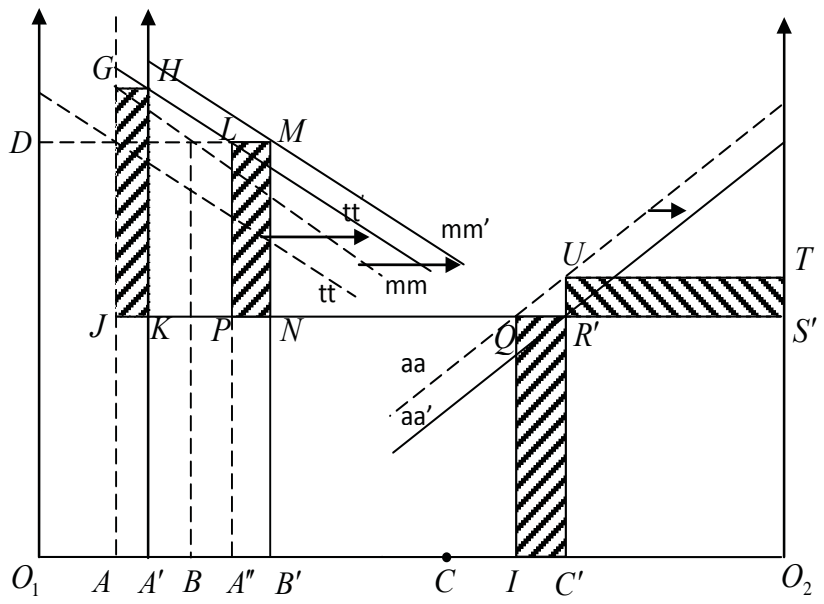

\section{General Equilibrium}

Now, we will conduct the comparative analysis of lowering the loan interest rate and increasing the unit investment of training a rural worker.

Total differentiation of equations (5), (11), (12) and (13) yields the following equation systems:

$$
\begin{aligned}
& \left(\begin{array}{cccc}
p_{1} h^{2} F_{L L}^{1} & 0 & 0 & h F_{L}^{1} \\
h F_{L}^{1} & 0 & 0 & -T^{\prime} \\
0 & -g F_{L L}^{3} & 1 & \lambda g^{\prime} F_{L}^{3} F_{T}^{2} T^{\prime} \\
h \bar{w} & w_{a} & -\left(\bar{L}_{3}-L_{3}\right) & 0
\end{array}\right)\left(\begin{array}{l}
d L_{1} \\
d L_{3} \\
d w_{a} \\
d p_{1}
\end{array}\right)=\left(\begin{array}{l}
c \\
0 \\
0 \\
0
\end{array}\right) d i \\
& +\left(\begin{array}{c}
\frac{h-c h^{\prime}}{h}(1+i)-p_{1} h F_{L L}^{1} h^{\prime} \\
-F_{L}^{1} L_{1} h^{\prime} \\
0 \\
-\left(L_{1}-\bar{L}_{1}\right) h^{\prime} \bar{w}
\end{array}\right) d c
\end{aligned}
$$


Define the determinant of the above square matrix as $\Delta$ and calculate $\Delta$ to obtain:

$$
\Delta=\left[g F_{L L}^{3}\left(\bar{L}_{3}-L_{3}\right)-w_{a}\right]\left[p_{1} h F_{L L}^{1} T^{\prime}+\left(h F_{L}^{1}\right)^{2}\right]<0
$$

Here $F_{L L}^{i}=\frac{\partial^{2} F^{i}}{\partial L_{i} \partial L_{i}}, i=1,2,3$

\subsection{The economic and environmental impacts of low interest rate policy}

The producer services sector will borrow all money from banks for training ruralurban migrants to meet the minimum human capital needed by the production of the producer services sector. The producer services sector will stop training the rural-urban migrants when they meet that human capital level. In this time, the unit cost of training a rural employee is given, that is $d c=0$. According to Cramer's rule with respect to $d i$ equation (14), we can solve the above equations system and get Table 1:

Table 1

The Economic and Environmental Impacts of Low Interest Rate Policy

\begin{tabular}{|c|c|c|c|c|c|c|}
\hline & $d L_{1}$ & $d L_{2}$ & $d L_{3}$ & $d L_{U}$ & $d p_{1}$ & $d E$ \\
\hline$d i$ & - & $/$ & + & {$[-]$} & + & + \\
\hline & $d h$ & $d T$ & $d w_{a}$ & $d Y_{1}$ & $d Y_{2}$ & $d Y_{3}$ \\
\hline$d i$ & $/$ & - & $/$ & - & - & + \\
\hline
\end{tabular}

Notes: "-" and "+" indicate that the changes of the exogenous variables will make the endogenous variables change in the opposite and same directions, respectively. "/" means the changes of exogenous variables have an ambiguous impact (or no impact) on endogenous variables;

" [-] "must satisfy the condition that $w_{a}-g F_{L L}^{3}\left(\bar{L}_{3}-L_{3}\right)<h \bar{w}$

According to Table 1, we establish the following results.

Proposition 1: In our assumed economy, government lowering of the interest rate of loans will contribute to the deterioration of the rural environment and exert the following economic impacts:

- The number of workers employed in the agricultural sector decreases, the number of rural-urban migrants employed in the producer services sector increases and urban unemployment increases on the condition that $w_{a}-g F_{L L}^{3}\left(\bar{L}_{3}-L_{3}\right)<h \bar{w}$;

- The outputs of the producer services and manufacturing sectors increase, while the output of agricultural sector decreases;

- The price of the producer services sector's product falls, and the demand of the intermediate input by the manufacturing sector increases. 
The mechanism of Proposition 1 can be described as follows. When the government lowers the interest rate of the training loan, the cost of the producer services sector making loans will decrease. Thus, more transferred labour will take the opportunity to be trained and the producer services sector will increase the employment of transferred rural labour, resulting in an increase in the output of the producer services sector. Then the manufacturing sector will increase the intermediate input and generate more output, which will deteriorate the rural environment. It is demonstrated that the government lowering the interest rate in order to support the human capital investment performed by the producer services sector does not solve the environmental problem, which should be noticed by the policy makers. Other subsidy policies leading to an increase in the amount of the employment of the producer services sector, as well as the human capital stock, will also attribute to the deterioration of the environment. The precondition of Proposition 1 is worth noting: "all money for training rural-urban migrants to meet the required minimum human capital level are borrowed by the producer services sector from banks. The producer services sector will stop training the rural-urban migrants when these migrants meet that human capital level." If this precondition cannot be met, the situation discussed in Proposition 1 will change.

\subsection{The economic and environmental impacts of firm's human capital investment}

Now, we discuss the economic and environmental impacts exerted by the firm's autonomous human capital investment. In this time, the interest rate of the loan is given, that is $d i=0$. The producer services sector will use the self-owned capital to train the rural-urban migrants to meet the necessary level of human capital according to their amount of business and financial status. Under the second plan, the firms are expected to create a training plan to fulfil their goals, and this plan will decide the unit training cost of transferred labour. According to Cramer's rule with respect to $d c$ equation (14), we can solve the above equations system and get Table 2 .

Table 2

The Economic and Environmental Impacts of Firm's Human Capital Investment

\begin{tabular}{|c|c|c|c|c|c|c|}
\hline & $d L_{1}$ & $d L_{2}$ & $d L_{3}$ & $d L_{U}$ & $d p_{1}$ & $d E$ \\
\hline$d i$ & - & $/$ & $/$ & $/$ & + & + \\
\hline & $d h$ & $d T$ & $d w_{a}$ & $d Y_{1}$ & $d Y_{2}$ & $d Y_{3}$ \\
\hline$d i$ & + & - & $/$ & $/$ & - & $/$ \\
\hline
\end{tabular}

Notes: "-"and "+"indicate that the changes of the exogenous variables will make the endogenous variables change in the opposite and same directions, respectively. "" means the changes of exogenous variables have an ambiguous impact (or no impact) on endogenous variables. 
According to Table 2, we establish the following results:

Proposition 2: In our assumed economy, the increased unit cost in the producer services sector of training a rural worker will improve the quality of the rural environment and exert the following economic impacts:

- The number of rural-urban migrants employed in the producer services sector decreases;

- The output of the manufacturing sector decreases;

- The price of the producer services sector's product rises, and the demand of the intermediate input by the manufacturing sector decreases.

Differently from the government's subsidy policies aimed at increasing the amount of employment, the enterprises increases the per capita human capital level according to their amount of business and financial status. When the enterprises use higher per capita human capital level and reduce the amount of the employees being trained, this does not mean that the human capital stock will increase. Thus, the output of the producer services sector does not necessarily increase and so does the output of the manufacturing sector (and pollution). The Proposition 2 claims that an increase in the unit cost of training a rural employee will result in a reduction of the human capital stock. The reason can be shown as follows: when the producer services sector increases the unit cost of training a rural labour, the unit cost of hiring a migrant by the producer services sector will increase. Thus, less transferred workers will take the opportunity to be trained and the producer services sector will decrease the employment of rural workers. The decrease of employment will also decrease the output of the producer services sector, and the manufacturing sector will correspondingly decrease intermediate inputs. Hence, the decrease of the output of manufacturing sector will improve the rural environment.

Comparing proposition 1 with proposition 2, we can conclude that when the producer services sector increases the unit cost of training a rural worker will improve the rural environment, which should be put in the top priority for the policy makers.

\subsection{The low interest rate policy, the loss of the agricultural sector due to the environmental pollution and the social welfare}

Now we will discuss the effects of government lowering of the interest rate of training loans on the loss of agricultural production due to the environmental pollution and the social welfare ${ }^{4}$.

4 The change of $c$ has ambiguous impacts on the loss of agricultural production due to the environmental pollution and the social utility level. 
The shaded area $S_{U T S^{\prime} R^{\prime}}$ in Figure1 can be illustrated by the following equation:

$$
S_{U T S^{\prime} R^{\prime}}=F^{3}-g(E) F^{3}
$$

Substituting equations (8) and (10) into equation (14), and total differentiation of equation (14), we can get:

$$
\frac{d S_{U T S^{\prime} R^{\prime}}}{d i}=(1-g) F_{L}^{3} \frac{d L_{3}}{d i}+g^{\prime} F^{3} \lambda F_{T}^{2} T^{\prime} \frac{d p_{1}}{d i}
$$

According to Table 1 and summarizing the above, we establish the following results.

Proposition 3: When $(1-g) F_{L}^{3} \frac{d L_{3}}{d i}>-g^{\prime} F^{3} \lambda F_{T}^{2} T^{\prime} \frac{d p_{1}}{d i}$, the government lowering of the loan interest rate will reduce the loss of agricultural production due to the environmental pollution; when $(1-g) F_{L}^{3} \frac{d L_{3}}{d i}<-g^{\prime} F^{3} \lambda F_{T}^{2} T^{\prime} \frac{d p_{1}}{d i}$, the government lowering of the loan interest rate will increase the loss of agricultural production due to the environmental pollution.

From equation (15), we know that the increase of the loss of agricultural production due to the environmental pollution is determined by two factors, the change of the employment in the agricultural sector and the change of the market price of producer service sector output. On the one hand, when the government lowers the interest rate of the loan, the producer services sector will increase the employment of rural transferred workers, leading to the number of workers employed in the agricultural sector decreasing. On the other hand, the government lowering the interest rate of the loan will decrease the market price of producer service sector output, meaning that the manufacturing sector will increase the production of intermediate inputs. Hence, the increase of the output of the manufacturing sector will decrease the quality of the rural environment and lower the marginal production value of the agricultural sector. The first term of equation (15), $(1-g) F_{L}^{3} \frac{d L_{3}}{d i}$ represents the positive effect of reducing the loss of agricultural production from environmental pollution, since the decrease of the employment of the agricultural sector reduces the loss. The second term of equation (15), $g^{\prime} F^{3} \lambda F_{T}^{2} T^{\prime} \frac{d p_{1}}{d i}$, which satisfies the equation $g^{\prime} F^{3} \lambda F_{T}^{2} T^{\prime} \frac{d p_{1}}{d i}=-g^{\prime} F^{3} \frac{d E}{d i}$, represents the negative effect of increasing the loss of agricultural production from environmental pollution, since a decrease in market price of producer service sector output leads to the deterioration of rural environment. If $(1-g) F_{L}^{3} \frac{d L_{3}}{d i}>-g^{\prime} F^{3} \lambda F_{T}^{2} T^{\prime} \frac{d p_{1}}{d i}$, that is, if the positive effect outweighs the negative effect, then the government's lowering of the loan interest rate will reduce the loss of agricultural production. Conversely, if 
$(1-g) F_{L}^{3} \frac{d L_{3}}{d i}<-g^{\prime} F^{3} \lambda F_{T}^{2} T^{\prime} \frac{d p_{1}}{d i}$, the positive effect is less than the negative effect and the opposite occurs. Proposition 3 can be illustrated by the following figure.

Figure 3

The Effects of the Government Lowering the Interest Rate of Training Loan on the Loss of Agricultural Production

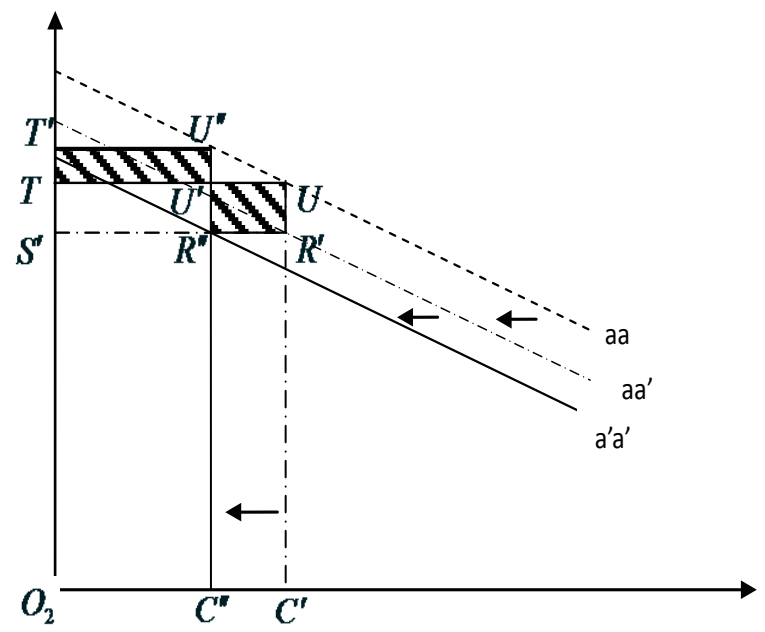

The illustration of proposition can be also shown by Figure 3 with the help of the right side of Figure 2 to evaluate the effects of lowering the interest rate on the loss of agricultural production. The government lowering the interest rate of the loan will decrease the employment of the agricultural sector, which is shown by a leftward shift of line $C^{\prime} U$ to the point $C^{\prime \prime}$ in Figure 3. According to Proposition 1, lowering the interest rate of the loan will also lead to the deterioration of rural environment, the consequence of which is further damage to agricultural production. These can be shown in Figure 3 by a leftward shift of the marginal production curve of agricultural sector, aa'. Here, we denote the new marginal production curve of agricultural sector as a'a'. We draw a line from $C^{\prime \prime}$ and perpendicular to the horizontal axis. It meets a' a', $T U$ and aa at $R^{\prime \prime}, U^{\prime}$ and $U^{\prime \prime}$, respectively. Draw a line passing $U^{\prime \prime}$ and parallel to the horizontal axis. It meets the vertical axis at $T^{\prime}$.Thus, the shaded area $S_{U R^{\prime} R^{\prime \prime} U^{\prime \prime}}$, express the reduced loss of the agricultural production due to decrease of the employment of the agricultural sector; The shaded area $S_{U^{\prime \prime} U^{\prime} T T}$, expresses the additional loss of the agricultural production due to the further deterioration of the rural environment by the increase of the output of the manufacturing sector. If $S_{U R^{\prime} R^{\prime \prime} U^{\prime \prime}}>S_{U^{\prime \prime} U^{\prime} T T}$, the first half of Proposition 3 can be established; if $S_{U R^{\prime} R^{\prime} U^{\prime \prime}}<S_{U^{\prime \prime} U^{\prime} T T}$, then the second half of Proposition 3 can be established. 
The demand side of the economy is represented by the expenditure function, which is defined as $e=e\left(p_{2}, U\right)$, where $U$ is the social utility level. Let $G$ equal the national income. Hence, the country's budget constraint can be stated as:

$$
e\left(p_{2}, U\right)=G
$$

The welfare effect can be obtained by totally differentiating equation (16) to yield:

Furthermore, we have:

$$
e_{U} d U=d G=p_{2} d Y_{2}+d Y_{3}
$$

$$
e_{U} \frac{d U}{d k}=\frac{d G}{d k}=\left(p_{2}-\lambda g^{\prime} F^{3}\right) F_{T}^{2} T^{\prime} \frac{d p_{1}}{d k}+g F_{L}^{3} \frac{d L_{3}}{d k}, k=i, c
$$

We build the results as follows.

Proposition 4: When $\left(p_{2}-\lambda g^{\prime} F^{3}\right) F_{T}^{2} T^{\prime}>-g F_{L}^{3} \frac{d L_{3}}{d i} / \frac{d p_{1}}{d i}$, the government lowering of the interest rate of the loan will lead to the decrease of the social utility level while when $\left(p_{2}-\lambda g^{\prime} F^{3}\right) F_{T}^{2} T^{\prime}<-g F_{L}^{3} \frac{d L_{3}}{d i} / \frac{d p_{1}}{d i}$, the opposite occurs, and the social utility level will increase.

From equation (17), we know that the change of the social utility level is determined by two factors, the change in employment of the agricultural sector and the change in the market price of producer service sector output. On the one hand, when the government lowers the loan interest rate, the producer services sector will increase the employment of rural transferred workers, in turn decreasing the number of workers employed in the agricultural sector. Therefore, the output of agricultural sector decreases. On the other hand, the government lowering of the interest rate of the loan will decrease the market price of producer services sector output, the consequence of which is that the manufacturing sector will increase the intermediate input. Hence, the increase of the output of manufacturing sector will generate more pollution and the agricultural sector will suffer from the deterioration of the rural environment. It is through this is the mechanism that the government lowering the interest rate of the loan will lead to the decrease of the social utility level on the condition $\left(p_{2}-\lambda g^{\prime} F^{3}\right) F_{T}^{2} T^{\prime}>-g F_{L}^{3} \frac{d L_{3}}{d i} / \frac{d p_{1}}{d i}$.

It is worthwhile to note that, if the government's efforts make the increase of the manufacturing production value less than the pollution damage to agricultural production, that is, when $\left(p_{2}-\lambda g^{\prime} F^{3}\right) F_{T}^{2} T^{\prime}>0$, the level of social utility will decrease. However, if the increase of the manufacturing production value is more than the total loss of the agricultural production value from environmental deterioration and the decrease of employment in the agricultural sector, the government lowering of the interest rate of the loan will increase the social utility level. 


\section{Conclusion}

The environmental effects of rural-urban migration and the relationship between human capital investment and rural-urban migration have been two popular issues in economic research. However, there is still no research attempting to combine ruralurban migration, vocational training of employees (or human capital investment), and the corresponding environmental effects into a unified framework. Integrating the above three factors into a unified theoretical framework will contribute to addressing the issues that prevail in the developing countries. The present paper presents a model involving rural-urban migration, vocational training of the rural-urban migrants employed by the producer services sector and environmental pollution into a general equilibrium framework. This is a necessary and crucial extension of the current researches, and the obtained results have significant implications to the real economy.

We conduct the comparative static analysis of lowering the training loan interest rate by the government and increasing the unit cost of training a rural worker by the producer services sector. There are several notable results. When the government lowers the interest rate of training loans, environmental conditions will worsen. The increase in the producer services sector unit cost of training a rural worker will increase the level of human capital of the rural people employed by this sector and improve rural environmental quality. That is, increasing the level of human capital will improve environmental quality. Thus, the governments in developing countries should make policies that guide enterprises to increase the unit cost of training an employed rural worker. In addition, some other economic results can be also derived. Under certain conditions, lowering the interest rate of the loan by the government will reduce pollution damage to agricultural production, but might decrease the social utility level as well. The above results can be used to implement development polices by policymakers.

It is clear that further analysis should consider the role of capital mobility and foreign direct investment. As it currently stands, other similar subsidy policies aimed at encouraging the enterprises for the human capital investment like the tax rebate and wage subsidy, and the comprehensive comparison among the different subsidy policies would be taken into consideration for the future studies. The present paper is an attempt to provide a foundation for future research.

\section{Appendix}

The determination of $p_{1}, L_{1}, L_{3}, w_{a}$ and $L_{U}$ :

The derivations of the equilibrium can be shown as follows: given that the values of the exogenous variables are $i$ and $c$, we can derive $p_{1}, L_{1}, L_{3}, w_{a}$ and $L_{U}$. When given $\bar{w}$ and exogenous variables $i$ and $c$, we can derive $L_{2}$ by solving equation (5). By solving equations (3) and (8), we also know $p_{1}$ and $L_{1}$. Substituting $p_{1}$ into 
equation (7), we know factor $T$. Substituting $L_{2}$ and $T$ into equation (4), $Y_{2}$ is derived. Given $Y_{2}$, from equation (10), we can know factor $E$. Substituting $E$ into equation (11) and $L_{1}, L_{2}$ into equation (13), only $w_{a}$ and $L_{3}$ are unknown variables. By solving the system of equations, we can derive $w_{a}$ and $L_{3}$. Finally, $L_{U}$ can be derived by substituting $w_{a}$, and $L_{3}$ into equation(12).

\section{References:}

Bhagwati, J. N., Srinivasan, T. N. (1977), "Education in a Job Ladder Model and the Fairnessin-Hiring Rule." Journal of Public Economics, Vol.7, No. 1, pp. 1-22.

Chao, C.-C. (2003), “Jobs, Production Linkages, and the Environment." Journal of Economics, Vol.79, pp.113-122.

Chaudhuri, S., Mukhopadhyay, U. (2006), "Pollution and Informal Sector: A Theoretical Analysis." Journal of Economic Integration, Vol. 21, No. 2, pp.363-378.

Copeland, B. R., Taylor, M. S. (1999), "Trade, Spatial Separation, and the Environment." Journal of International Economics, Vol. 47, No.1, pp. 137-168.

Dean, J. M., Gangopadhyay, S. (1997), "Export bans, environmental protection, and unemployment." Review of Development Economics, 1997, Vol.1, pp. 324-336.

Djajic, S. (1985), "Human Capital, Minimum Wage and Unemployment: A Harris-Todaro Model of Developed Open Economy." Economica, Vol. 52, pp. 491-508.

Galor, O., Moav, O. (2004), "From Physical to Human Capital Accumulation: Inequality in the Process of Development." Review of Economic Studies, Vol. 71, No. 4, pp. 1001-1026.

Grinols, E. L. (1991), "Unemployment and Foreign Capital: the Relative Opportunity Costs of Domestic Labor and Welfare." Economica, Vol. 62, pp.59-78.

Grossman, G. M., Krueger, B. A. (1995), "Economic Growth and the Environment." Quarterly Journal of Economics, Vol. 110, No. 2, pp. 353-377.

Gupta, M. R. (1993), "Rural-Urban Migration, Informal Sector and Development Policies." Journal of Development Economics, Vol. 41, pp. 137-151.

Harris, J. R., Todaro, M. (1970), "Migration, Unemployment and Development: A Two Sector Analysis." American Economic Review, Vol. 40, pp. 126-42.

Liu Z. (2011)," Why is Service Share So Small in China's Developed Region?" Journal of Nanjing University (Philosophy, Humanities and Social Sciences), 2011, No. 3, pp. 13-19 (in Chinese).

Papola, T. (1981), Urban Informal Sector in a Developing Economy. New Delhi: Vikas Publishing House.

Romatet, E. (1983), "Calcutta's Informal Sector: Theory and Reality." Economic and Political Weekly, 18 (50): pp.2115-2128.

Samanta, S. (2003), "Training, Unemployment and Fiscal Subsidy: A Harris-Todaro Approach." SSRN Working Paper Series, http://ssrn.com/abstract=471981 or doi:10.2139/ssrn. 471981. Nov. 2003.

Tawada, M., Nakamura, Z. (2009), International Trade and Economic Dynamics. Berlin, Heidelberg: Springer, pp. 87-99.

Tawada, M., Sun, S. (2010), "Urban Pollution, Unemployment and National Welfare in a Dualistic Economy." Review of Development Economics, Vol.14, No. 2, pp. 311-322.

Xiaochun Li, Xiaoying Qian (2011), "Economic Analysis on the Urban-rural Disparity in Human Capital in China." South African Journal of Economics, Vol.79, No. 2, pp.146-160. 